\title{
Ossification of the ligamentum flavum: a unique report of a Hispanic woman
}

\author{
Lana D. Christiano, M.D., Rachid Assina, M.D., and Ira M. Goldstein, M.D. \\ Department of Neurological Surgery, New Jersey Medical School, University of Medicine and Dentistry of \\ New Jersey, Newark, New Jersey
}

\begin{abstract}
Ossification of the ligamentum flavum (OLF) is a disease of ectopic bone formation within the ligamentum flavum, which may result in mass effect and neurological compromise. The low thoracic region is the most common region of occurrence, and this is followed by the cervical, then lumbar, spine. The prevalence of OLF is significantly higher in the Japanese population compared with other nationalities and has a male preponderance. Ossification of the ligamentum flavum has been reported in association with the more common ligamentous pathological entities - ossification of the posterior longitudinal ligament and diffuse idiopathic skeletal hyperostosis. These latter two conditions have been linked to several metabolic processes, and a possible genetic basis has been hypothesized. Here, the authors present a unique case of OLF of the cervical spine in a patient with idiopathic hypercalcemia.
\end{abstract} (DOI: 10.3171/2011.1.FOCUS10266)

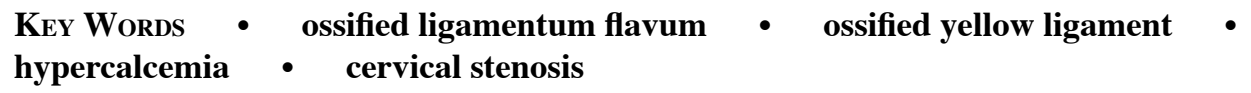

$\mathrm{T}$ HE ligamentum flava are broad paired spinal ligaments that connect the adjacent laminae of the vertebral column extending from C-2 to $\mathrm{S}-1 .^{9,27,52}$ These ligaments can undergo uni- or bilateral hypertrophy, calcification, or ossification..$^{30}$ Ossification of the ligamentum flavum is an acquired degenerative disease that was first described by Polgar $^{36}$ in 1920 on lateral radiograms. It occurs through endochondral ossification of hypertrophied fibrous tissue within the ligaments.

Ossification of the ligamentum flavum is a relatively rare disease, and there are insufficient controlled epidemiological data in the literature. Ossification of the ligamentum flavum is reported to affect $20 \%$ of Asians older than 65 years of age..$^{10}$ Although OLF has been reported as endemic to Japan, reports from outside of this endemic area-North Africa, ${ }^{2,5,13}$ the Middle East, ${ }^{3}$ India, ${ }^{14,15,42}$ Caribbean, ${ }^{34}$ Europe, ${ }^{4,7,10,32,33,35,43}$ and North America $^{20,27,31,41,48,49}$ - have been increasingly reported in the literature. However, the Japanese population remains the largest population affected, with $88.8 \%$ of the reports of OLF in the literature based on Japanese patients, and Caucasians are the second-most common, comprising $8.2 \%$ of the reports. ${ }^{27}$

The low thoracic spine is the most common location

Abbreviations used in this paper: CLF = calcification of the ligamentum flavum; DISH = diffuse idiopathic skeletal hyperostosis; OLF $=$ ossification of the ligamentum flavum; OPLL = ossification of the posterior longitudinal ligament; $\mathrm{PTH}=$ parathyroid hormone. of OLF, T9-12 being the most affected region..$^{10,29,34,38,49,52}$ The predominance of OLF in the low thoracic spine is thought to be associated with the transitional segment between the end of the rib cage and the thoracolumbar junction resulting in increased motion, degeneration, and microtrauma to the ligamentum flava. ${ }^{10}$ In a study by Guo et al., ${ }^{10} 1736$ Chinese patients underwent MR imaging of the spinal axis to screen for OLF. In patients with OLF, the lesions were located in the cervical region in $4.3 \%$, the thoracic region in $95.6 \%$ (52.2\% had disease T9-12), and the lumbar region in $0.1 \% .^{10}$ The authors also found that $15 \%$ of patients had noncontiguous OLF lesions and recommended thorough screening prior to treatment.

\section{Case Report}

History. This 45-year-old Hispanic woman had a 5-year history of idiopathic hypercalcemia, chronic kidney disease, and nephrolithiasis after left urethral stenting. She presented with a progressive 1.5-year history of neck pain and left arm weakness and numbness. She also complained of gait instability and apraxia of the hands. She had no history of trauma. On presentation to the emergency department, her serum creatinine $(3.2 \mathrm{mg} / \mathrm{dl})$ and calcium $(15.2 \mathrm{mg} / \mathrm{dl})$ levels were elevated above baseline $(1.9-2.2 \mathrm{mg} / \mathrm{dl}$ and $11-12 \mathrm{mg} / \mathrm{dl}$, respectively), and her serum glomerular filtration rate $(15 \mathrm{ml} /$ minute) was lower than her baseline ( $28 \mathrm{ml} /$ minute). 
Examination. On examination we observed a wellnourished Hispanic woman with no apparent distress. Her neck was supple with mild tenderness along the cervical spine and cervicothoracic junction of the column. Neurologically, she exhibited muscle weakness (Grade 4-/5) and sensory deficit of the left upper and lower extremities with long tract findings on the left as well. The right upper and lower extremities were normal.

Admission CT scanning (Fig. 1) and MR imaging (Fig. 2) revealed hypertrophy and ossification of the ligamentum flavum, bilaterally, from C-2 to T-3, resulting in severe C3-7 canal stenosis with severe cord compression. The anteroposterior diameter of the canal at C-5 measured approximately $4.2 \mathrm{~mm}$. The dura mater was also calcified at the same levels mentioned above. There was no subluxation, neural foraminal narrowing, or vertebral joint hypertrophy. We found no evidence of DISH, OPLL, and other ligamentous pathologies or ectopic bone formations.

Operation. The patient was diagnosed with idiopathic hypercalcemia, likely due to increased gastrointestinal tract absorption of calcium. Her renal function improved with aggressive hydration and cinacalcet (Sensipar, Amgen Inc). Once her medication levels were optimized, she was brought to the operating room. Anesthesia was induced following fiberoptic intubation, the patient was placed in the Mayfield head holder, and somatosensory and motor evoked potentials were established at baseline, intraoperatively, and postoperatively. Instrumentation was applied from C-2 to C-7. A C2-7 laminectomy was then performed using a high-speed drill, a forward-angled curette, and a Kerrison rongeur. A markedly hypertrophic, partly ossified ligamentum flavum was then encountered. Resection was performed in piecemeal fashion at C7-T1 with rongeurs until the dura could be appreciated. Blunt dissection was conducted (Fig. 3 and Video 1).

VIDEO 1. Intraoperative video recorded using the operative microscope. Cranial is the left lower portion of the screen and caudal in right upper portion of the screen. The ossified part of the ligamentum flavum is removed with a combination of blunt and sharp dissection. A curette is used to identify the plane lat- erally. Metzenbaum scissors are then used to sharply amputate the ossified ligamentum flavum, which is then reflected cranially and dissected away from the dura with blunt dissection using a No. 4 Penfield instrument. Click here to view with Windows Media Player. Click here to view with Quicktime.

We observed several areas of OLF that were indistinguishable from underlying calcified dura (Fig. 4). A small durotomy was repaired in primary fashion with muscle patch and fibrin glue after we failed to reapproximate the calcified dura with suture. Once a generous decompression was achieved from C-2 through T-1 and confirmed at each level by direct palpation with a Woodson device, the instrumentation was extended to T-2 caudally and the construct was then completed with titanium rods and cross-link connectors. Finally, we applied graft material that included local and iliac crest nonstructural autograft, nonstructural allograft, and an internal bone growth stimulator. Both somatosensory and motor evoked potentials were stable throughout the surgery. The patient was transferred to the neurosurgical intensive care unit in stable condition.

Postoperative Course. The patient experienced complete resolution of her neck pain, weakness, and numbness of the left upper extremity. Cervical CT scanning revealed a wide and adequate decompression of the spinal cord, especially at C5-6. On her discharge on postoperative Day 7, motor examination revealed no weakness; Grade 5/5 strength in all muscle groups; and no upper motor signs. At the 1-month follow-up visit, the patient reported significant improvement in her mobility, gait, and left-hand clumsiness.

Pathological review of the tissue submitted was inconclusive. Calcification and crystalline deposits were identified, but the composition of the crystals could not be elucidated as the specimen was placed in formalin. Nodules of giant cells and granulomatous reaction were also seen.

\section{Discussion}

\section{Ossification of the Ligamentum Flavum}

The ligamentum flava are broad paired spinal liga-
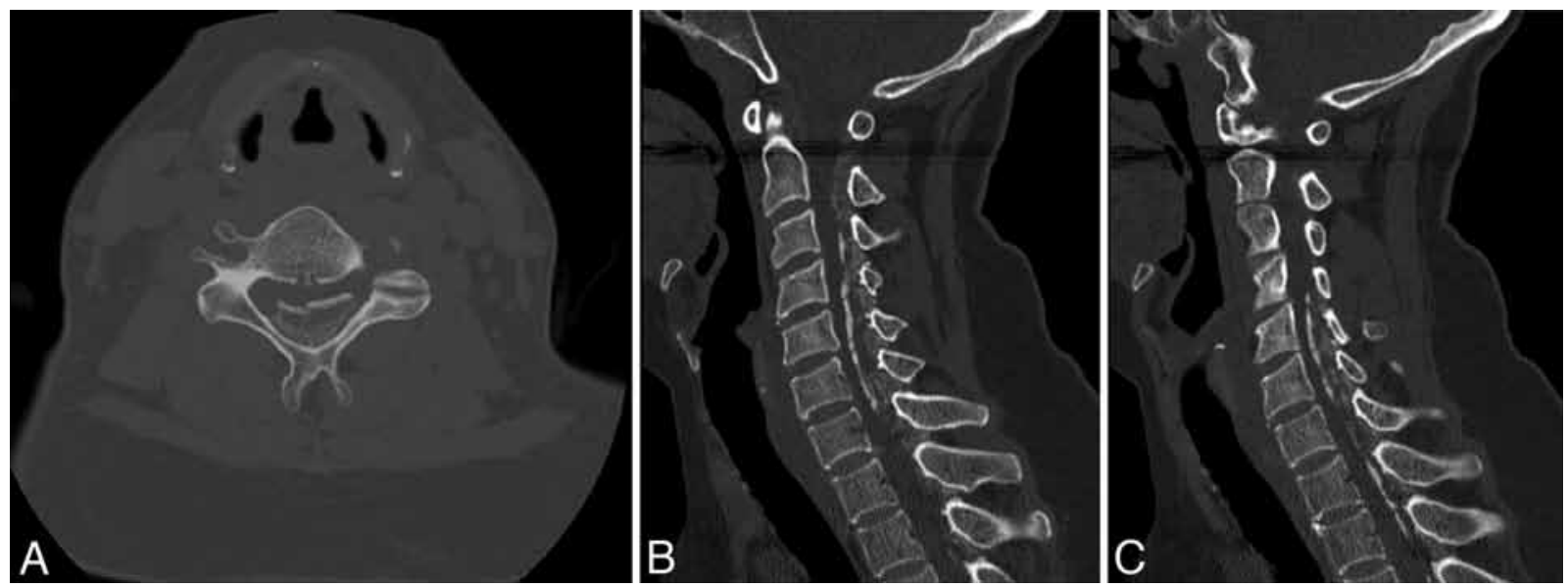

FIG. 1. A: Axial CT scan at the level of the C-6 neural foramen demonstrating significant posteromedial compression, extending toward the left nerve root. B and C: Sagittal CT scans demonstrating the contiguous nature of the ossified ligamentum flava extending from $\mathrm{C} 2-\mathrm{T} 3$. 

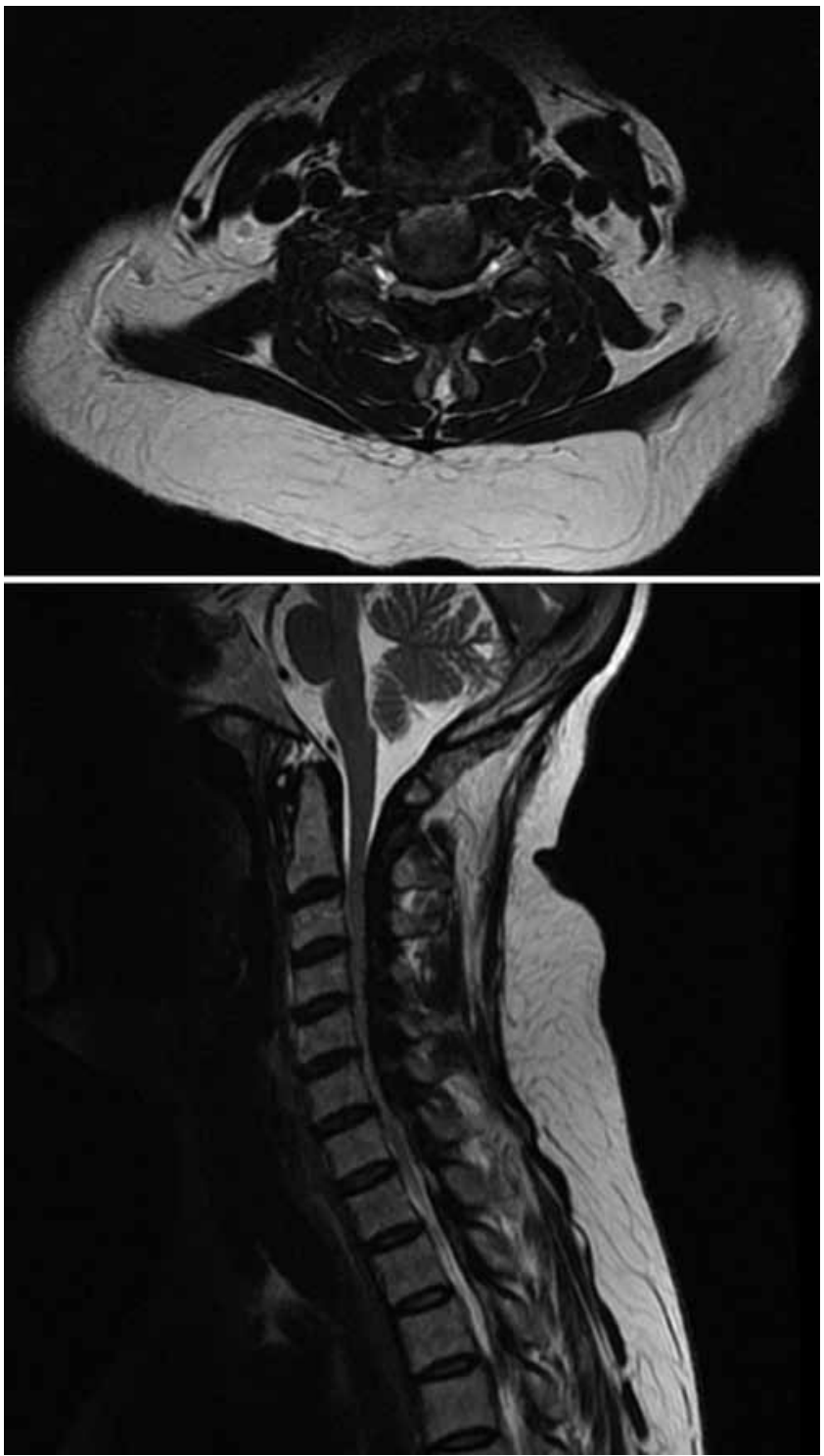

Fig. 2. Upper: Axial CT scan of the cervical spine demonstrating significant cord compression. Lower: Sagittal MR image again demonstrating the extent of spinal cord compression. Despite the extent of compression, there is no intramedullary hyperintense signal.

ments that connect the adjacent laminae of the vertebral column extending from C-2 to S-1.9,27,52 Each pair attaches to the anteroinferior surface of the superior lamina and the posterosuperior surface of the inferior lamina. ${ }^{9,49}$ The ligamentum flavum originates bilaterally at the articular processes on either side of the nerve roots and extends posteriorly along the lamina to midline. ${ }^{9}$ At the midline, the ligamentum flavum is partially fused with the contralateral side. ${ }^{9}$ It is composed of longitudinal elastic connective tissue. ${ }^{27}$ The ligamentum flavum functions as an elastic band aiding the spinal column in resuming neutral position after flexion and extension motion., ${ }^{9,49}$

Ossification of the ligamentum flavum is characterized by replacement of the structure by ectopic bone formation through endochondral ossification. ${ }^{34,49,52}$ It is an enthesopathy in which the normal fibrous structure of the

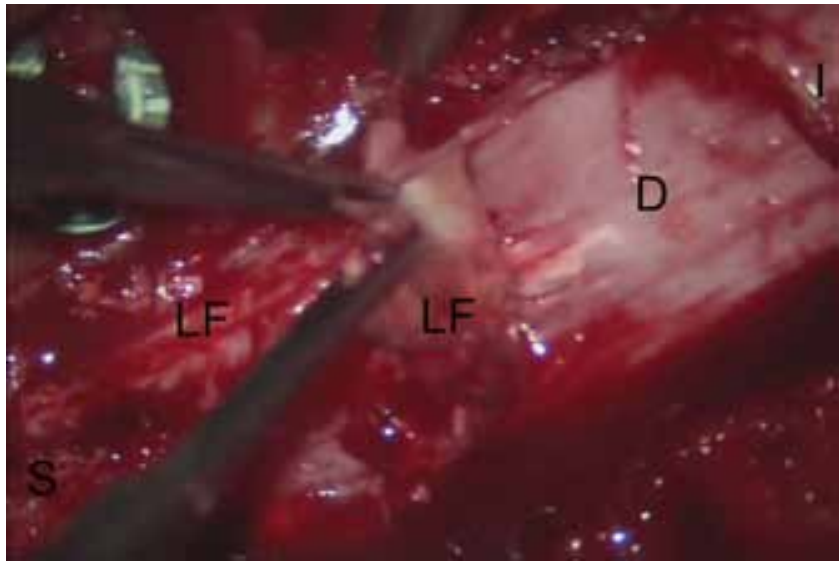

FIG. 3. Intraoperative photograph of the removal of ossified ligamentum flavum (LF) bilaterally. The laminectomy has already been performed and the ossified ligamentum flava are being removed from inferior to superior in a stripping manor using blunt and sharp dissection techniques. $\mathrm{D}=$ dura; $\mathrm{I}=$ inferior; $\mathrm{S}=$ superior.

ligamentum flavum is lost and replaced by hypertrophied fibrous tissue, rich in fibrocartilaginous cells, that has an increased affinity for calcium deposition and serves as promoter for chondrometaplasia. ${ }^{22}$ Ossification results from progressive replacement of the hypertrophied ligamentum flavum by lamellar bone through endochondral ossification of the vascularized fibrocartilaginous tissue starting at the densely adherent ligamentous-osseous junction (enthesis) then extending along the ventral aspect of the ligament. ${ }^{22}$ Histological studies have found ossification along the yellow ligaments, fewer elastic fibers, and more fibrocartilaginous cells, premature osteons, and osteoblasts. ${ }^{47}$ Heterotopic ossification occurs by fibroblast proliferation, followed by chondroblast formation in which the chondroblasts transform into osteoblasts. ${ }^{44}$ In a study by Zhong et al., ${ }^{52}$ cultured OLF cells were shown to express osteocalcin (a maker of osteoblasts) and collagen Type II (a marker for chondrocytes), confirming that OLF cells have osteoblast and chondrocyte phenotypes. ${ }^{52}$

Ossification of the ligamentum flavum has been di-

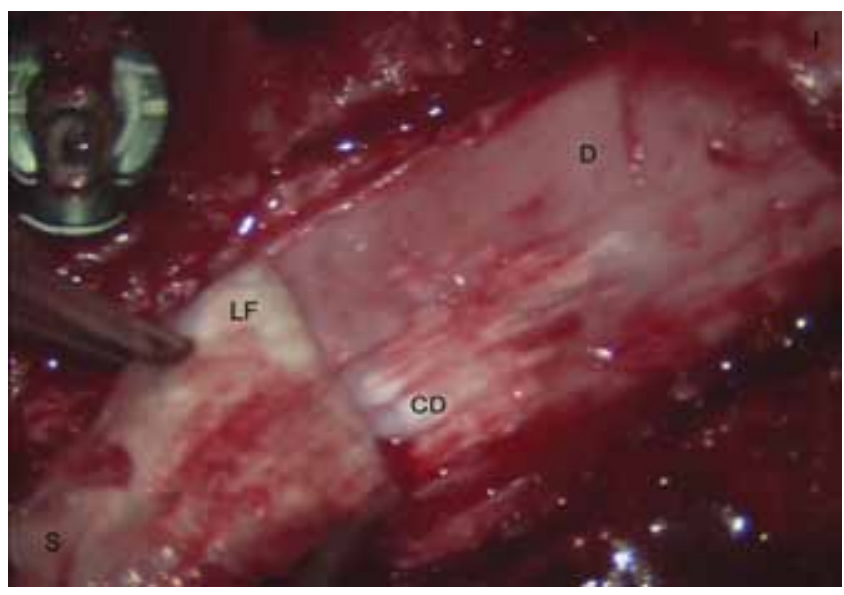

Fig. 4. Intraoperative photograph of the removal of ossified ligamentum flavum. In some places the ossified ligamentum flavum was adherent to the dura, and a dissection plane could not be identified. $C D=$ calcified dura. 
vided into 5 types based on extent/location of the ossification..$^{29}$ The lateral type, Type I, is located only laterally at the origin of the ligamentum flavum at the articular processes. ${ }^{29}$ The extended type, Type II, extends from the lateral origin of the ligamentum flavum to the interlaminar portion of the ligamentum flavum..$^{29}$ The enlarged type, Type III, protrudes into the canal posterolaterally but is not fused in the midline. ${ }^{29}$ The fused type, Type $\mathrm{IV}$, consists of bilateral ossified ligaments that are fused at the midline with a groove at the fusion in midline. ${ }^{29}$ Type V, the tuberous type, occurs when the fused ossified ligamentum flavum forms a "tuberous" mass posteriorly in the midline, which protrudes into the spinal canal. ${ }^{29}$

Computed tomography and MR imaging are the imaging modalities of choice. Radiography generally lacks the sensitivity to identify OLF. Computed tomography, with the use of bone windows, produces the most accurate information regarding location, size, and extent of the disease. Ossification of the ligamentum flavum begins laterally at the facet capsule and grows medially, as previously discussed. This process results in the V-shaped appearance of calcification on axial CT scans. ${ }^{34}$ This is also the reason that the calcification is best identified on sagittal CT scans. Additionally, CT is useful in determining whether the dura is involved in OLF. Muthukumar ${ }^{29} \mathrm{de}-$ fined two reliable signs on CT scans that demarcate dural involvement in OLF: the tram track sign and the comma sign. The tram track sign is a hyperdense bony excrescence with a hypodense center. ${ }^{29}$ The comma sign is ossification of one-half of the circumference of the dura. ${ }^{29}$ This is important to identify preoperatively because this may change the approach/manner of the laminectomy and decompression. Magnetic resonance imaging is useful in demonstrating the extent of spinal cord compression and identifying underlying spinal cord injury (the high signal intensity on T2-weighted images) and the compressive lesion. ${ }^{43}$

Calcification of the ligamentum flavum is often confused with OLF. Histologically, CLF is composed of degenerated ligamentum flavum and with calcified granules consisting of calcium pyrophosphate dihydrate and hydroxyapatite, whereas OLF contains ectopic bone produced through endochondral ossification. ${ }^{18,50}$ An additional difference is that CLF often affects women in the cervical spine, whereas OLF is more predominant in men in the thoracic and lumbar distributions.$^{18}$ Radiographically, CLF reportedly involves only one interlaminar segment and is not contiguous with or only partially in contact with the laminae, which is most readily distinguished on sagittal CT scanning. ${ }^{49}$ Ultimately, the distinction between OLF and CLF is based on the pathological specimen.

\section{Management}

Ossification of the ligamentum flavum presents most often as a myeloradiculopathy. Patients usually present first with sensory deficits, followed by limb weakness, and later gait disturbance. ${ }^{34,45}$ Lateral OLF lesions have been associated, although rarely, with radiculopathy due to nerve root compression. ${ }^{34}$ As previously mentioned, OLF often can occur in a noncontiguous manner. We advise, prior to surgical intervention, a thorough screening of the spinal axis and confirmation that the clinical symptoms match the location of disease.

To date there are no pharmacological therapies for OLF. At best, management of the underlying cause may slow progression of the disease. The majority of these patients, however, do not come to medical attention until they are symptomatic. Once myelopathy develops, the only treatment option is surgical decompression.

The literature has described laminoplasty, laminectomy, and laminectomy with fusion as surgical options. Li et al. ${ }^{22}$ performed decompressive surgery in 40 patients for thoracic OLF. They compared laminoplasty to laminectomy with fusion. They did not undertake laminectomy as a stand-alone procedure due to the reports of late-onset kyphosis. ${ }^{22}$ They performed 4 laminoplasty procedures: symptoms in 1 patient improved (25\%) and symptoms in 3 patients $(75 \%)$ were unchanged or worse (and 2 of these 3 patients developed late-onset kyphosis). In the laminectomy and fusion group, $83 \%$ of the patients had a "good or fair" outcome and symptoms in $17 \%$ were unchanged or worse. The authors concluded that laminoplasty yielded an insufficient decompression, and hence the poor result, was associated with kyphotic deformity, and was technically difficult given the adherence of the OLF to the dura. ${ }^{22}$ They found decompressive laminectomy and fusion to be the superior surgical management. ${ }^{22}$ This procedure allows aggressive, wide decompression and limits motion and thus microtrauma, which some postulate may be the source of the OLF.22

Of note, an ossified ligamentum flavum can be very adherent to the dura, with rates in the literature ranging from $11 \%$ to $62 \% .^{29}$ Specifically, the enlarged, fused, and tuberous types are associated with a high incidence of dural ossification. ${ }^{29}$ The benefit of complete resection of the ossified ligamentum flavum and involved dura, compared with decompression leaving a portion of ossified dura, has not been described in the literature. While complete resection in OLF, including the involved dura, is ideal, wound healing and CSF leakage can pose a substantial problem even with a dural graft, tissue glue, and possible lumbar drainage. ${ }^{29}$

Different laminectomy techniques have been posed to address the adherent dura: an en bloc approach, a "separating" laminectomy, and microsurgical drilling. The en bloc laminectomy is performed in a standard fashion by drilling through the lamina bilaterally and then removing the bone in a lobster-tail manner. ${ }^{22}$ The separating laminectomy involves removing the spinous process, drilling the midline down to the dura, and bilateral drilling of the mid-facet joint in an attempt to remove the ossified mass, medial to lateral. ${ }^{22}$ Finally, complete resection of the lamina and ossified ligamentum flavum through microsurgical drilling has also been advocated. ${ }^{8}$

The only factor associated with poor neurological outcome is the presence preoperatively of an intramedullary hyperintense signal on MR imaging. ${ }^{49}$ Dural ossification has been associated with a complicated hospital course including higher rates of CSF leakage and meningitis, but no effect on long-term neurological function has been reported. ${ }^{25}$ Factors associated with good outcomes included a short duration of mild clinical symptoms, ${ }^{1,38}$ 
single-level disease ${ }^{21}$ and unilateral lesions. ${ }^{21}$ Complications noted in the literature include paralysis, likely due to spinal cord manipulation in adherent, stenotic cases; epidural hematoma; CSF leakage; and delayed kyphosis. ${ }^{25,49,51}$

\section{Metabolic Associations}

The cause of OLF remains unclear, despite its identification 90 years ago. It has been described in association with hyperostotic syndromes including OPLL, DISH, and ankylosing spondylosis..$^{26,27,43}$ It has been thought to be linked to metabolic derangements including diabetes mellitus, hyperinsulinism, impaired glucose tolerance, obesity, Paget disease, hemochromatosis, fluorosis, X-linked hypophosphatemia, and hypoparathyroidism..$^{12,24,27,43,47}$ Additionally, mechanical stress, trauma, and genetics have been suggested as contributing factors associated with OLF. ${ }^{29}$

A number of factors in our case are unique: the patient is a young, Hispanic female with idiopathic hypercalcemia and OLF in nearly the entire cervical spine, extending from C3-T2. Wang et al. ${ }^{47}$ studied the calcium level in ligamentum flavum in normal patients, those with degenerative disease, and those with ossified disease. They found statistically significant higher levels of calcium in the ligamentum flavum in patients with OLF and degenerative disease compared with normal patients. Interestingly, they also evaluated the serum levels of calcium in the same 3 patient groups and found no difference. ${ }^{47} \mathrm{Vi}$ tamin D-resistant rickets has also been associated with OLF. Patients with this disorder, however, have low serum phosphate and slightly lower serum calcium levels. ${ }^{46}$

Our patient suffered from chronic kidney disease secondary to idiopathic hypercalcemia; the cause of chronic kidney disease in this case was 2 -fold. She had previously suffered from kidney stones requiring placement of ureteral stents. Additionally, she had intrinsic renal failure demonstrated by elevated serum creatinine and decreased glomerular filtration rate. Renal insufficiency secondary to hypercalcemia can be to the result of different mechanisms including arteriolar vasoconstriction, alterations in glomerular permeability, nephrocalcinosis, and nephrolithiasis. ${ }^{28}$ Parathyroid hormone has an interesting effect on bone formation. It regulates the serum calcium levels indirectly by stimulating osteoclasts. When given in continuous manner, PTH causes bone resorption and an increase in serum calcium, but when administered in an intermittent fashion, it causes bone formation and a decrease in serum calcium. ${ }^{19}$ Additionally, PTH-related protein modulates proliferation and differentiation of chondrocytes and subsequently endochondral bone formation. ${ }^{40}$ Both PTH and PTH-related protein have been suggested as possible links to ossification of spinal ligaments.

Hyperinsulinemia is another metabolic abnormality associated with ectopic bone formation within the spinal ligaments, specifically in OPLL. ${ }^{39}$ Specifically, noninsulin-dependent diabetes mellitus has a higher incidence of OPLL and DISH compared with insulin-dependent diabetes. This difference is thought to be secondary to the higher levels of circulating insulin in patients with NIDDM. ${ }^{39}$ The suggested roles insulin plays in hyperostosis include stimulating intestinal calcium absorption ${ }^{39}$ and stimulating the proliferation of bone morphogenic protein-2-induced osteogenic differentiation. ${ }^{23}$ Insulin-like growth factor-I is upregulated in NIDDM as well as acromegaly and has been linked to increased bone mineral density. ${ }^{16,37}$

As previously noted, OLF is seen in association with other hyperostotic syndromes such as OPLL. In a review by Guo et al. ${ }^{11} 13$ studies of tandem OPLL and OLF were reviewed. They found that $53 \%$ of the patients had thoracic OPLL and thoracic OLF, 23\% of which were at the same level. Despite OPLL commonly occurring in the cervical spine, tandem cervical OPLL and cervical OLF only occurred in $1.4 \%$ of the patients. The remaining $45.6 \%$ had noncontiguous lesions-OPLL and OLF in different spinal regions.

Kawaguchi et al. ${ }^{17}$ demonstrated that growth factors play a significant role in hyperostosis of the spinal ligaments. They performed immunohistochemical analysis on surgically obtained posterior longitudinal ligament during decompression surgery for OPLL. They found bone morphogenic protein-2 and transforming growth factor- $\beta$ at the site of ligamentous ossification, but not in normal ligament obtained in the same patient, ${ }^{17}$ indicating these growth factors play an essential role in ossification of the spinal ligaments. The upregulation of these elements within the OLF (as well as in OPLL) ${ }^{6}$ suggests a role of inflammation in the development of this condition and may serve as a target for future medical therapies in halting its progression.

\section{Conclusions}

Ossification of the ligamentum flavum is a well-established disease entity, but there is much to be learned about the underlying mechanism. We present a case of a young, Hispanic female with idiopathic hypercalcemia and OLF from C2-T3.

\section{Disclosure}

Dr. Goldstein is a consultant for Zimmer Spine and Alphatec Spine.

Author contributions to the study and manuscript preparation include the following. Conception and design: all authors. Acquisition of data: Christiano, Assina. Analysis and interpretation of data: all authors. Drafting the article: all authors. Critically revising the article: all authors. Reviewed final version of the manuscript and approved it for submission: all authors. Administrative/technical/ material support: Christiano, Goldstein. Study supervision: Goldstein.

\section{Acknowledgment}

We would like to acknowledge Dr. Ada Baisre De Leon, in neuropathology, who assisted in the pathological diagnosis of this patient.

\section{References}

1. Aizawa T, Sato T, Sasaki H, Kusakabe T, Morozumi N, Kokubun S: Thoracic myelopathy caused by ossification of the ligamentum flavum: clinical features and surgical results in the Japanese population. J Neurosurg Spine 5:514-519, 2006

2. Akhaddar A, Mansouri A, Zrara I, Gazzaz M, Maftah M, Mostarchid $\mathrm{B}$, et al: Thoracic spinal cord compression by liga- 
mentum flavum ossifications. Joint Bone Spine 69:319-323, 2002

3. al-Orainy IA, Kolawole T: Ossification of the ligament flavum. Eur J Radiol 29:76-82, 1998

4. Arafat QW, Jackowski A, Chavda SV, West RJ: Case report: ossification of the thoracic ligamenta flava in a Caucasian: a rare cause of myelopathy. Br J Radiol 66:1193-1196, 1993

5. Ben Hamouda K, Jemel H, Haouet S, Khaldi M: Thoracic myelopathy caused by ossification of the ligamentum flavum: a report of 18 cases. J Neurosurg 99 (2 Suppl):157-161, 2003

6. Bonniaud P, Margetts PJ, Ask K, Flanders K, Gauldie J, Kolb M: TGF-beta and Smad3 signaling link inflammation to chronic fibrogenesis. J Immunol 175:5390-5395, 2005

7. Celli P, Caroli E, Trillò G, Ferrante L: Ossification of the ligamentum flavum in a Caucasian. Case report. J Neurosurg Sci 46:96-99, 2002

8. Chou YC, Lee CC, Yen PS, Lin JF, Su CF, Lin SZ, et al: Cough induced by ossification of the ligamentum flavum in the high cervical spine. Case report. J Neurosurg 100 (4 Suppl Spine):364-366, 2004

9. Gray H: Gray's Anatomy of the Human Body, ed 20. Philadelphia: Lea \& Febiger, 1918

10. Guo JJ, Luk KD, Karppinen J, Yang H, Cheung KM: Prevalence, distribution, and morphology of ossification of the ligamentum flavum: a population study of one thousand seven hundred thirty-six magnetic resonance imaging scans. Spine 35:51-56, 2010

11. Guo JJ, Yang HL, Cheung KM, Tang TS, Luk KD: Classification and management of the tandem ossification of the posterior longitudinal ligament and flaval ligament. Chin Med J (Engl) 122:219-224, 2009

12. Hepgül K, Nicoll JA, Coakham HB: Spinal cord compression due to pagetic spinal stenosis with involvement of extradural soft tissues: a case report. Surg Neurol 35:143-146, 1991

13. Jaffan I, Abu-Serieh B, Duprez T, Cosnard G, Raftopoulos C: Unusual CT/MR features of putative ligamentum flavum ossification in a North African woman. Br J Radiol 79:e67-e70, 2006

14. Jaisuresh K, Vinodh Kumar P, Sundaravadivelu V: Thoracic myelopathy due to ossified ligamentum flavum. Calicut Med J 5:e1, 2007

15. Jayakumar PN, Devi BI, Bhat DI, Das BS: Thoracic cord compression due to ossified hypertrophied ligamentum flavum. Neurol India 50:286-289, 2002

16. Kanazawa I, Yamaguchi T, Sugimoto T: Serum insulin-like growth factor-I is a marker for assessing the severity of vertebral fractures in postmenopausal women with type 2 diabetes mellitus. Osteoporos Int [epub ahead of print], 2010

17. Kawaguchi H, Kurokawa T, Hoshino Y, Kawahara H, Ogata E, Matsumoto T: Immunohistochemical demonstration of bone morphogenetic protein-2 and transforming growth factor-beta in the ossification of the posterior longitudinal ligament of the cervical spine. Spine 17 (3 Suppl):S33-S36, 1992

18. Khan MH, Smith PN, Donaldson WF III: Acute quadriparesis caused by calcification of the entire cervical ligamentum flavum in a white female-report of an unusual case and a brief review of the literature: case report. Spine 30:E687-E691, 2005

19. Kroll MH: Parathyroid hormone temporal effects on bone formation and resorption. Bull Math Biol 62:163-188, 2000

20. Kruse JJ, Awasthi D, Harris M, Waguespack A: Ossification of the ligamentum flavum as a cause of myelopathy in North America: report of three cases. J Spinal Disord 13:22-25, 2000

21. Kuh SU, Kim YS, Cho YE, Jin BH, Kim KS, Yoon YS, et al: Contributing factors affecting the prognosis surgical outcome for thoracic OLF. Eur Spine J 15:485-491, 2006

22. Li F, Chen Q, Xu K: Surgical treatment of 40 patients with thoracic ossification of the ligamentum flavum. J Neurosurg Spine 4:191-197, 2006
L. D. Christiano, R. Assina, and I. M. Goldstein

23. Li H, Liu D, Zhao CQ, Jiang LS, Dai LY: Insulin potentiates the proliferation and bone morphogenetic protein-2-induced osteogenic differentiation of rat spinal ligament cells via extracellular signal-regulated kinase and phosphatidylinositol 3-kinase. Spine 33:2394-2402, 2008

24. Matsui H, Katoh Y, Tsuji H: Untreated hypophosphatemic vitamin D-resistant rickets with symptomatic ossification of the ligamentum flavum. J Spinal Disord 4:110-113, 1991

25. Miyakoshi N, Shimada Y, Suzuki T, Hongo M, Kasukawa Y, Okada K, et al: Factors related to long-term outcome after decompressive surgery for ossification of the ligamentum flavum of the thoracic spine. J Neurosurg 99 (3 Suppl):251-256, 2003

26. Miyazawa N, Akiyama I: Ossification of the ligamentum flavum of the cervical spine. J Neurosurg Sci 51:139-144, 2007

27. Mobbs RJ, Dvorak M: Ossification of the ligamentum flavum: diet and genetics. J Clin Neurosci 14:703-705, 2007

28. Moysés-Neto M, Guimarães FM, Ayoub FH, Vieira-Neto OM, Costa JA, Dantas M: Acute renal failure and hypercalcemia. Ren Fail 28:153-159, 2006

29. Muthukumar N: Dural ossification in ossification of the ligamentum flavum: a preliminary report. Spine 34:2654-2661, 2009

30. Okada K, Oka S, Tohge K, Ono K, Yonenobu K, Hosoya T: Thoracic myelopathy caused by ossification of the ligamentum flavum. Clinicopathologic study and surgical treatment. Spine 16:280-287, 1991

31. Omojola MF, Cardoso ER, Fox AJ, Drake CG, Durward QJ: Thoracic myelopathy secondary to ossified ligamentum flavum. J Neurosurg 56:448-450, 1982

32. Pantazis G, Tsitsopoulos P, Bibis A, Mihas C, Chatzistamou I, Kouzelis C: Symptomatic ossification of the ligamentum flavum at the lumbar spine: a retrospective study. Spine 33:306311,2008

33. Parekh HC, Gurusinghe NT, Perera SS, Prabhu SS: Ossification of the ligamentum flavum in a Caucasian: case report. Br J Neurosurg 7:687-690, 1993

34. Pascal-Moussellard H, Cabre P, Smadja D, Catonné Y: Symptomatic ossification of the ligamentum flavum: a clinical series from the French Antilles. Spine 30:E400-E405, 2005

35. Payer M, Bruder E, Fischer JA, Benini A: Thoracic myelopathy due to enlarged ossified yellow ligaments. Case report and review of the literature. J Neurosurg 92 (1 Suppl):105-108, 2000

36. Polgar F: Uber interakuelle wirbelverkalkung. Fortschr Geb Rongenstr Nuklearmed Erganzungsband 40:292-298, 1920

37. Rivadeneira F, Houwing-Duistermaat JJ, Vaessen N, VergeerDrop JM, Hofman A, Pols HA, et al: Association between an insulin-like growth factor I gene promoter polymorphism and bone mineral density in the elderly: the Rotterdam Study. J Clin Endocrinol Metab 88:3878-3884, 2003

38. Sato T, Kokubun S, Tanaka Y, Ishii Y: Thoracic myelopathy in the Japanese: epidemiological and clinical observations on the cases in Miyagi Prefecture. Tohoku J Exp Med 184:1-11, 1998

39. Shingyouchi Y, Nagahama A, Niida M: Ligamentous ossification of the cervical spine in the late middle-aged Japanese men. Its relation to body mass index and glucose metabolism. Spine 21:2474-2478, 1996

40. Suda N: Parathyroid hormone-related protein (PTHrP) as a regulating factor of endochondral bone formation. Oral Dis 3: 229-231, 1997

41. Suojanen JN, Lipson SJ: Spinal cord compression secondary to ossified ligamentum flavum. J Spinal Disord 2:238-240, 1989

42. Trivedi P, Behari S, Paul L, Banerji D, Jain VK, Chhabra DK: Thoracic myelopathy secondary to ossified ligamentum flavum. Acta Neurochir (Wien) 143:775-782, 2001

43. van Oostenbrugge RJ, Herpers MJ, de Kruijk JR: Spinal cord 


\section{Ossification of the ligamentum flavum}

compression caused by unusual location and extension of ossified ligamenta flava in a Caucasian male. A case report and literature review. Spine 24:486-488, 1999

44. Vanden Bossche L, Vanderstraeten G: Heterotopic ossification: a review. J Rehabil Med 37:129-136, 2005

45. Vasudevan A, Knuckey NW: Ossification of the ligamentum flavum. J Clin Neurosci 9:311-313, 2002

46. Velan GJ, Currier BL, Clarke BL, Yaszemski MJ: Ossification of the posterior longitudinal ligament in vitamin D-resistant rickets: case report and review of the literature. Spine 26:590-593, 2001

47. Wang Z, Li XD, Li MQ, Wang QP: Changes in basic metabolic elements associated with the degeneration and ossification of ligamenta flava. J Spinal Cord Med 31:279-284, 2008

48. Wiseman DB, Stokes JK, Toselli RM: Paraparesis in a black man brought on by ossification of the ligamentum flavum: case report and review of the literature. J Spinal Disord Tech 15:542-545, 2002

49. Xu R, Sciubba DM, Gokaslan ZL, Bydon A: Ossification of the ligamentum flavum in a Caucasian man. Case report. J Neurosurg Spine 9:427-437, 2008

50. Yamagami T, Kawano N, Nakano H: Calcification of the cervical ligamentum flavum-case report. Neurol Med Chir (Tokyo) 40:234-238, 2000
51. Yamazaki M, Okawa A, Fujiyoshi T, Furuya T, Koda M: Posterior decompression with instrumented fusion for thoracic myelopathy caused by ossification of the posterior longitudinal ligament. Eur Spine J 19:691-698, 2010

52. Zhong ZM, Chen JT: Phenotypic characterization of ligamentum flavum cells from patients with ossification of ligamentum flavum. Yonsei Med J 50:375-379, 2009

Manuscript submitted November 12, 2010.

Accepted January 12, 2011.

Supplemental online information:

Video: http://mfile.akamai.com/21490/wmv/digitalwbc.download. akamai.com/21492/wm.digitalsource-na-regional/focus10-266. asx (Media Player).

http://mfile.akamai.com/21488/mov/digitalwbc.download akamai. com/21492/qt.digitalsource-global/focus10-266.mov (Quicktime).

Address correspondence to: Lana D. Christiano, M.D., 90 Bergen Street, Suite 8100, Department of Neurological Surgery, New Jersey Medical School, University of Medicine and Dentistry of New Jersey, Newark, New Jersey 07103. email: docmitchel@yahoo.com. 